\title{
(4HS) \\ Fabrication of Various Electroless Ni-P Alloy/Multiwalled Carbon Nanotube Composite Films and Their Frictional Properties
}

\author{
Susumu Arai, ${ }^{a, *, z}$ Toshihiko Sato, ${ }^{\text {a }}$ and Morinobu Endo ${ }^{\text {b }}$ \\ ${ }^{a}$ Department of Chemistry and Material Engineering and ${ }^{b}$ Department of Electrical and Electronic \\ Engineering, Faculty of Engineering, Shinshu University, Nagano 380-8553, Japan
}

\begin{abstract}
$\mathrm{Ni}-\mathrm{P}$ alloy/multiwalled carbon nanotube (MWCNT) composite films were fabricated using an electroless plating method, and their microstructures and frictional properties were studied. MWCNTs of various sizes were used and three kinds of electroless plating baths were prepared to form the Ni-P alloy matrix with varying phosphorus contents. Heat-treatments of the composite films were also carried out. The microstructures of the composite films were examined by scanning electron microscopy and X-ray diffraction. Frictional properties of the composite films were investigated using a ball-on-plate method. Ni-P alloy/MWCNT composite films with different phosphorus contents, classified as high phosphorus (12-13 mass \%), medium phosphorus (6-8 mass \%), and low phosphorus (2-4 mass \%) types, were fabricated using electroless deposition. The Ni-P alloy/MWCNT composite films showed lower friction coefficients compared to Ni-P alloy films with the same phosphorus content both before and after heattreatment. The friction coefficients of the films were affected by the microstructure and size of the MWCNTs, the composition of the Ni-P alloy matrix, and the heat-treatment.

(C) 2010 The Electrochemical Society. [DOI: 10.1149/1.3486096] All rights reserved.
\end{abstract}

Manuscript submitted June 24, 2010; revised manuscript received August 3, 2010. Published September 16, 2010.

Electroless plated Ni-P alloy films ${ }^{1}$ have many desirable properties, such as good wear resistance, corrosion resistance, and electromagnetic shielding, and are widely used in industrial products. For convenience, such films are classified into three categories based on the phosphorus content. The low phosphorus type contains around 2-4 mass \% (around 4-7 atom \%) phosphorus and has relatively good crystallinity of the face-centered cubic nickel. It exhibits magnetic properties and has been used as electromagnetic shielding in electronic devices such as personal computers. The medium phosphorus type contains around 6-10 mass \% (around 11-17 atom \%) phosphorus and has a semiamorphous or amorphous structure. It possesses good wear and corrosion resistance and has been most widely used as protective films of mechanical parts. The high phosphorus type contains 11-13 mass \% (19-22 atom \%) phosphorus and has an amorphous structure. It has superior corrosion resistance and is nonmagnetic and accordingly has been used as an undercoating on hard disk substrates.

Carbon nanotubes $(\mathrm{CNTs})^{2,3}$ have excellent mechanical characteristics, such as high tensile strength and elastic modulus. Research into practical applications of CNTs, such as the preparation of resin/ CNT, ceramic/CNT, and metal/CNT composites, has been actively pursued. Recently, the fabrication of metal/CNT composites has been attempted using plating techniques. ${ }^{4-9}$ In previous studies on electroless CNT composite plating, superior tribological properties of electroless Ni-P alloy/multiwalled carbon nanotube (MWCNT) composite coatings were reported. ${ }^{10-16}$ In these studies, only $20-40$ $\mathrm{nm}$ diameter MWCNTs were examined and the effects of the size or species of MWCNTs were not examined. Furthermore, the effects of phosphorus content on the properties of the Ni-P alloy/MWCNT composite films have not been investigated. As mentioned above, the effects of phosphorus content on the microstructure and properties of the Ni-P alloy/MWCNT composite films are not only of academic interest but are also important for practical uses. In this study, we fabricated electroless plated Ni-P alloy/MWCNT composite films with varying phosphorus contents using MWCNTs of various sizes and evaluated their frictional properties.

\section{Experimental}

The electroless Ni-P alloy/MWCNT composite plating bath compositions used are shown in Table I. Three different baths were prepared to form the Ni-P alloy/MWCNT composite films with dif-

\footnotetext{
* Electrochemical Society Active Member

${ }^{\mathrm{z}}$ E-mail: araisun@shinshu-u.ac.jp
}

ferent phosphorus contents (high phosphorus, medium phosphorus, and low phosphorus types, as described above). Sodium hypophosphite and sodium citrate were used as the reducing and complexing agents, respectively. To disperse the MWCNTs in the plating baths homogeneously, a stearyl trimethyl ammonium chloride dispersant was added to the plating baths with stirring and ultrasonic agitation. The $\mathrm{pH}$ values of all the baths were adjusted to 9 . The specifications of the MWCNTs used in the present study are shown in Table II. vapor grown carbon fibers (VGCFs), vapor grown carbon nanofibers (VGNFs) (Showa Denko Co. Ltd.), and Iljin (Iljin Nanotec Co. Ltd.) are all commercially available. Cut-VGCFs and cut-VGNFs were prepared by mechanically cutting the VGCFs and VGNFs using a blender. ${ }^{17}$ The lengths of the cut-VGCFs and cut-VGNFs were estimated by scanning electron microscopy (SEM) observations using field-emission-scanning electron microscopes (FESEMs, JEOL JSM-7000F and Hitachi High-Technologies S-4100). The VGCFs and VGNFs, and therefore the cut-VGCFs and cut-VGNFs also, were graphitized MWCNTs ${ }^{18}$ (heat-treated at $2800^{\circ} \mathrm{C}$ in argon gas for $30 \mathrm{~min})$. A pure copper plate $(3.3 \times 3 \times 0.3 \mathrm{~cm})$ was used as the substrate. Pretreatment of the substrate was carried out using a normal two-step method (sensitization and activation). A 4.4 $\times 10^{-2} \mathrm{M} \mathrm{SnCl}_{2} \cdot \mathrm{H}_{2} \mathrm{O}+0.12 \mathrm{M} \mathrm{HCl}$ solution and a $6 \times 10^{-4} \mathrm{M}$ $\mathrm{PdCl}_{2}+0.12 \mathrm{M} \mathrm{HCl}$ solution were used for sensitization and activation, respectively. Electroless plating was carried out at $40^{\circ} \mathrm{C}$ for the medium phosphorus-type films and at $50^{\circ} \mathrm{C}$ for the high and low phosphorus-type films with stirrer agitation. Heat-treatment of the composite films was performed using an IR heating furnace (ULVAC Technologies Mila-3000) in vacuum at $400^{\circ} \mathrm{C}$ for $60 \mathrm{~min}$. The microstructures of the films were examined using an X-ray diffractometer (XRD, Shimadzu Seisakusho XRD-6000) and the FESEMs mentioned above. A specialized sample preparation system (crosssectional polisher, JEOL SM-09010) was used to prepare crosssectional samples for FESEM observations. The phosphorus content in the Ni-P alloy matrix was measured using an electron probe X-ray microanalyzer (Shimadzu Seisakusho EPMA-1610). The tribological properties were measured using a ball-on-plate-type reciprocating friction abrasion test machine (Nissho Electric Works MMS-2419). An alumina ball $(6 \mathrm{~mm}$ in diameter, $\mathrm{Hv}=1500)$ was used as the counter surface. The reciprocating friction stroke was 4 $\mathrm{mm}$, and the tests were conducted under a normal load of $2 \mathrm{~N}$. The average sliding speed was $0.5 \mathrm{~mm} \mathrm{~s}^{-1}$ and the number of cycles was 50. All measurements were performed under ambient conditions without any lubricants. During the tests, the friction coefficient was measured continuously using a load cell. 


\begin{tabular}{|c|c|c|c|}
\hline Reagents & High phosphorus-type bath & Medium phosphorus-type bath & Low phosphorus-type bath \\
\hline $\mathrm{NiSO}_{4} \cdot 6 \mathrm{H}_{2} \mathrm{O}$ & $0.1 \mathrm{M}$ & $0.1 \mathrm{M}$ & $0.16 \mathrm{M}$ \\
\hline $\mathrm{NaH}_{2} \mathrm{PO}_{2} \cdot \mathrm{H}_{2} \mathrm{O}$ & $0.2 \mathrm{M}$ & $0.2 \mathrm{M}$ & $0.05 \mathrm{M}$ \\
\hline $\mathrm{C}_{6} \mathrm{H}_{5} \mathrm{Na}_{3} \mathrm{O}_{7}$ & $0.5 \mathrm{M}$ & $0.2 \mathrm{M}$ & $0.08 \mathrm{M}$ \\
\hline$\left(\mathrm{NH}_{4}\right)_{2} \mathrm{SO}_{4}$ & $0.5 \mathrm{M}$ & $0.5 \mathrm{M}$ & \\
\hline Stearyl trimethyl ammonium chloride & $1.7 \times 10^{-3} \mathrm{M}$ & $1.7 \times 10^{-3} \mathrm{M}$ & $1.7 \times 10^{-3} \mathrm{M}$ \\
\hline MWCNTs & $0.2 \mathrm{~g} \mathrm{dm}^{-3}$ & $0.2 \mathrm{~g} \mathrm{dm}^{-3}$ & $0.2 \mathrm{~g} \mathrm{dm}^{-3}$ \\
\hline
\end{tabular}

\section{Results and Discussion}

Figure 1 shows surface SEM images of the electroless Ni-P alloy/MWCNT composite films for various reaction times. The MWCNTs used were the cut-VGCFs and the plating bath used was the high phosphorus-type bath. The number of cut-VGCFs on the film surface increased with increasing reaction time. Thus, the cutVGCFs were incorporated in the film simultaneously with Ni-P alloy film growth. Figure 2 shows a cross-sectional SEM micrograph of the Ni-P alloy/cut-VGCF composite film electroless-deposited from the high phosphorus-type bath. The film thickness is $\sim 4 \mu \mathrm{m}$. The black areas are cross sections of the cut-VGCFs. Thus, the cut-VGCFs were embedded in the Ni-P alloy film matrix. Because there are no defects such as voids, the composite film is compact.

Figure 3 shows surface SEM images of electroless Ni-P alloy/ various MWCNT composite films from the high phosphorus-type bath. For comparison, a Ni-P alloy film without MWCNTs is also shown (Fig. 3a). The deposition rates were $\sim 3 \mu \mathrm{m} \mathrm{h}^{-1}$ for the $\mathrm{Ni}-\mathrm{P}$ alloy/Iljin composite film and $1 \mu \mathrm{m} \mathrm{h}^{-1}$ for the other composite films. The magnification of the Ni-P alloy/Iljin composite

\begin{tabular}{lccc}
\hline \multicolumn{3}{c}{ Table II. Specifications of MWCNTs used. } & \\
MWCNTs & $\begin{array}{c}\text { Diameter } \\
(\mathrm{nm})\end{array}$ & $\begin{array}{c}\text { Length } \\
(\mu \mathrm{m})\end{array}$ & Supplier \\
\hline VGCF & 150 & $10-15$ & Showa Denko \\
Cut-VGCF & 150 & $3-4$ & Showa Denko \\
VGNF & 80 & $10-15$ & Showa Denko \\
Cut-VGNF & 80 & $1-2$ & Showa Denko \\
Iljin & 15 & $10-15$ & Iljin Nanotech
\end{tabular}

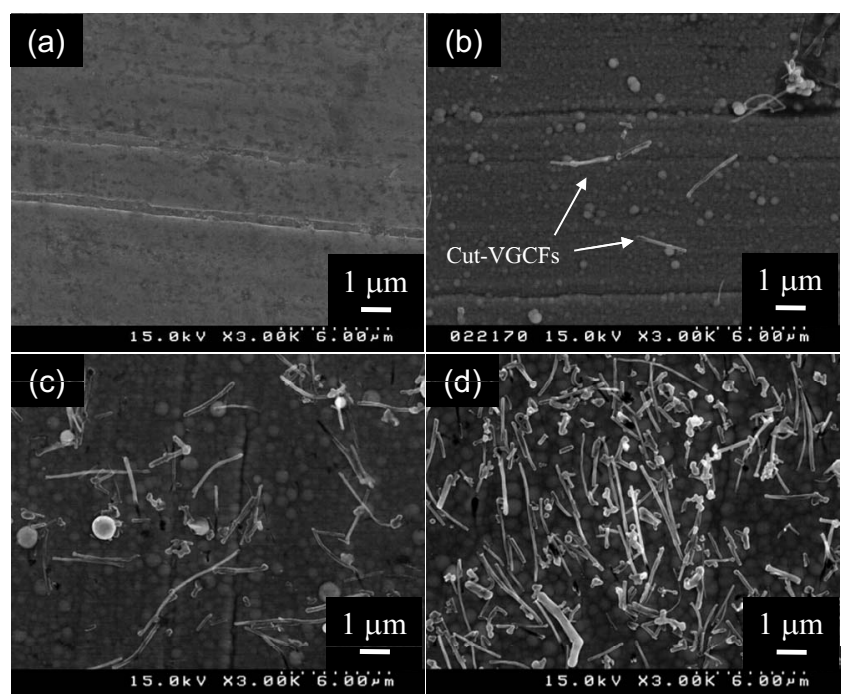

Figure 1. Surface SEM images showing the growth of electroless deposited $\mathrm{Ni}-\mathrm{P}$ alloy/MWCNT composite films (a) before electroless deposition, (b) after $10 \mathrm{~min}$, (c) after $30 \mathrm{~min}$, and (d) after $60 \mathrm{~min}$. The MWCNTs used are cut-VGCFs. The electroless plating bath used is the high phosphorus-type bath. film is higher than that of the others (Fig. 3f) because Iljins are very thin and could not be observed at the magnification used for the other samples. The thicknesses of these films are all in the 4-5 $\mu \mathrm{m}$ range. The phosphorus content in the Ni-P alloy matrix of these films was 12-13 mass \%. Therefore, these films have a high phosphorus-type Ni-P alloy matrix. In all the films, the MWCNTs were distributed homogeneously across the film surface without aggregation. Cross-sectional observations indicated that all the films were compact and the MWCNTs were distributed homogeneously in the composite films. Thus, electroless Ni-P alloy/MWCNT composite films were successfully fabricated from the high phosphorus-type bath using the different types of MWCNTs.

Electroless Ni-P alloy/MWCNT composite films were also successfully fabricated from the medium phosphorus-type bath using the different types of MWCNTs. The deposition rates were $\sim 2 \mu \mathrm{m} \mathrm{h}^{-1}$ for the Ni-P alloy/lljin composite film and $\sim 1.5 \mu \mathrm{m} \mathrm{h}^{-1}$ for the other films. Figure 4 shows various surface SEM images of electroless Ni-P alloy/MWCNT composite films from the medium phosphorus-type bath. For comparison, a Ni-P alloy film without MWCNTs is also shown (Fig. 4a). The magnification used for the Ni-P alloy/Iljin composite film is higher than that for the other films (Fig. 4f). The thicknesses of these films are all 4-5 $\mu \mathrm{m}$. The phosphorus content in the Ni-P alloy matrix of these films was 7-8 mass \%. Therefore, these films have a medium phosphorus-type Ni-P alloy matrix. All the MWCNTs were also distributed homogeneously across the film surfaces without aggregation. Cross-sectional observations confirmed that all the films were compact and the MWCNTs were distributed homogeneously in the composite films. Thus, electroless Ni-P alloy/MWCNT composite films with high and medium phosphorus-type Ni-P alloy matrixes containing the different types of MWCNTs used in this study could be successfully fabricated.

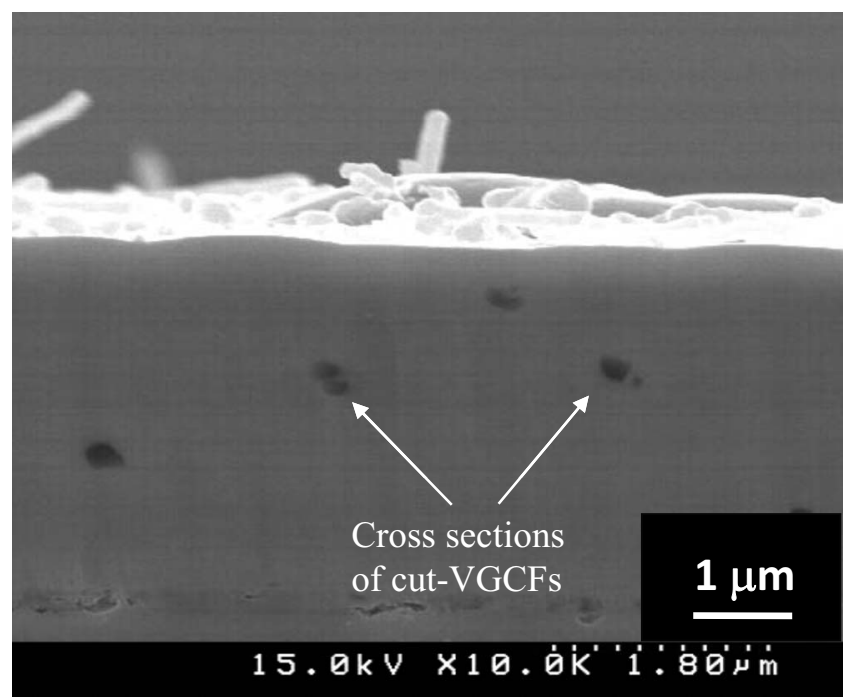

Figure 2. Cross-sectional SEM image of high phosphorus-type Ni-P alloy/ cut-VGCF composite film. Film thickness is $\sim 4 \mu \mathrm{m}$. 

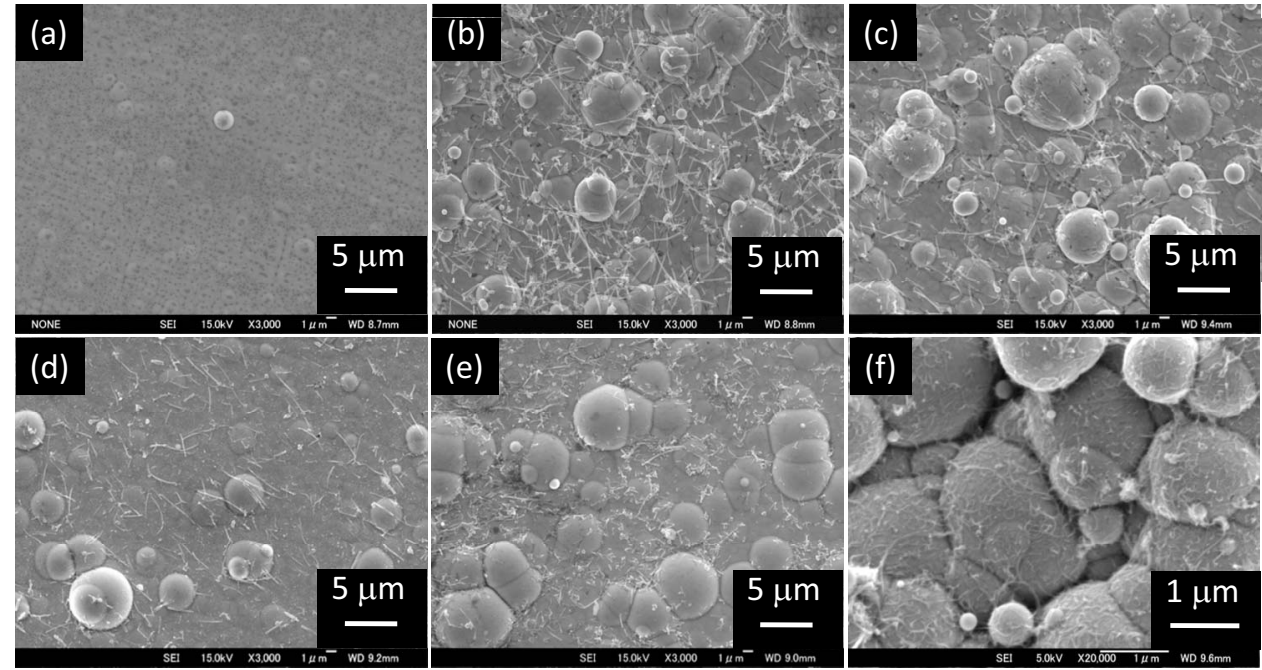

Figure 3. Surface SEM images of high phosphorus-type Ni-P alloy/various MWCNT composite films: (a) Ni-P alloy, (b) Ni-P alloy/VGCF composite, (c) Ni-P alloy/cut-VGCF composite, (d) Ni-P alloy/VGNF composite, (e) Ni-P alloy/ cut-VGNF composite, and (f) Ni-P alloy/ Iljin composite film. Film thickness of all films is $\sim 4 \mu \mathrm{m}$.
In contrast, Ni-P alloy/MWCNT composite films could not be obtained from the low phosphorus-type bath containing VGCFs, cutVGCFs, VGNFs, and cut-VGCFs. These MWCNTs were not sufficiently incorporated in the Ni-P alloy films. Only the Iljins could be successfully incorporated in the Ni-P alloy matrix, yielding Ni-P alloy/Iljin composite films from the low phosphorus-type bath. The deposition rate was $\sim 3.5 \mu \mathrm{m} \mathrm{h}^{-1}$ for the Ni-P alloy/Iljin composite film. Figure 5 shows surface SEM images of the films fabricated using the low phosphorus-type bath. For comparison, a Ni-P alloy film without MWCNTs is also included (Fig. 5a). The thicknesses of these films are all 4-5 $\mu \mathrm{m}$. The phosphorus content in the Ni-P alloy matrix of these films were $2-4$ mass $\%$. The Iljins are homogeneously distributed on the surface of the Ni-P alloy/lijin composite film. Cross-sectional observations indicated that these films were compact and the Iljins were distributed homogeneously in the composite films. Comparing the composition of the low phosphorus-type bath with those of the high and medium phosphorus-type baths, it was observed that no $\left(\mathrm{NH}_{4}\right)_{2} \mathrm{SO}_{4}$ is present in the low phosphorustype bath (Table I). Therefore, the existence of $\left(\mathrm{NH}_{4}\right)_{2} \mathrm{SO}_{4}$ might be related to the incorporation of MWCNTs. We plan to examine in detail the cause for the failure to incorporate the VGCFS, cutVGCFs, VGNFs, and cut-VGNFs in the low phosphorus-type Ni-P films in a future work. However, low phosphorus-type Ni-P alloy/ Iljin composite films were successfully fabricated.

Figure 6 shows surface SEM images of the electroless medium phosphorus-type $\mathrm{Ni}-\mathrm{P}$ alloy/cut-VGCF composite film before and after heat-treatment. The surface morphology remained largely unchanged after heat-treatment. After heat-treatment, cut-VGCFs were still present on the film surface and no defects such as cracks were observed on the surface. Surface morphologies of all the other types of electroless Ni-P alloy/MWCNT composite films also did not change significantly after heat-treatment.

Figure 7 shows typical XRD patterns of the electroless Ni-P alloy/MWCNT composite films. Figure 7a and b shows XRD patterns from the high phosphorus-type Ni-P alloy/VGCF composite films before and after heat-treatment. The XRD patterns of the high phosphorus-type Ni-P alloy/MWCNT composite films using the other types of MWCNTs before and after heat-treatment were almost the same, as shown in Fig. 7a and b, respectively. Figure 7c-f shows XRD patterns from the medium phosphorus-type Ni-P alloy/ Iljin and low phosphorus-type Ni-P alloy/Iljin composite films before and after heat-treatment, respectively. The XRD patterns of the medium-type Ni-P alloy/MWCNT composite films using other types of MWCNTs before and after heat-treatment were almost the same as in Fig. 7c and d. No obvious peaks assignable to MWCNTs were observed in any of the diffraction patterns. The peak strengths of the MWCNTs were very weak. As indicated, Fig. 7a, c, and e shows typical diffraction patterns of electroless Ni-P alloy films before heat-treatment for the high, medium, and low phosphorus types, respectively. The crystallinity of the face-centered cubic nickel in the Ni-P alloy matrix increased with decreasing phosphorus content in the alloy matrix. Figure $7 b, d$, and f shows typical
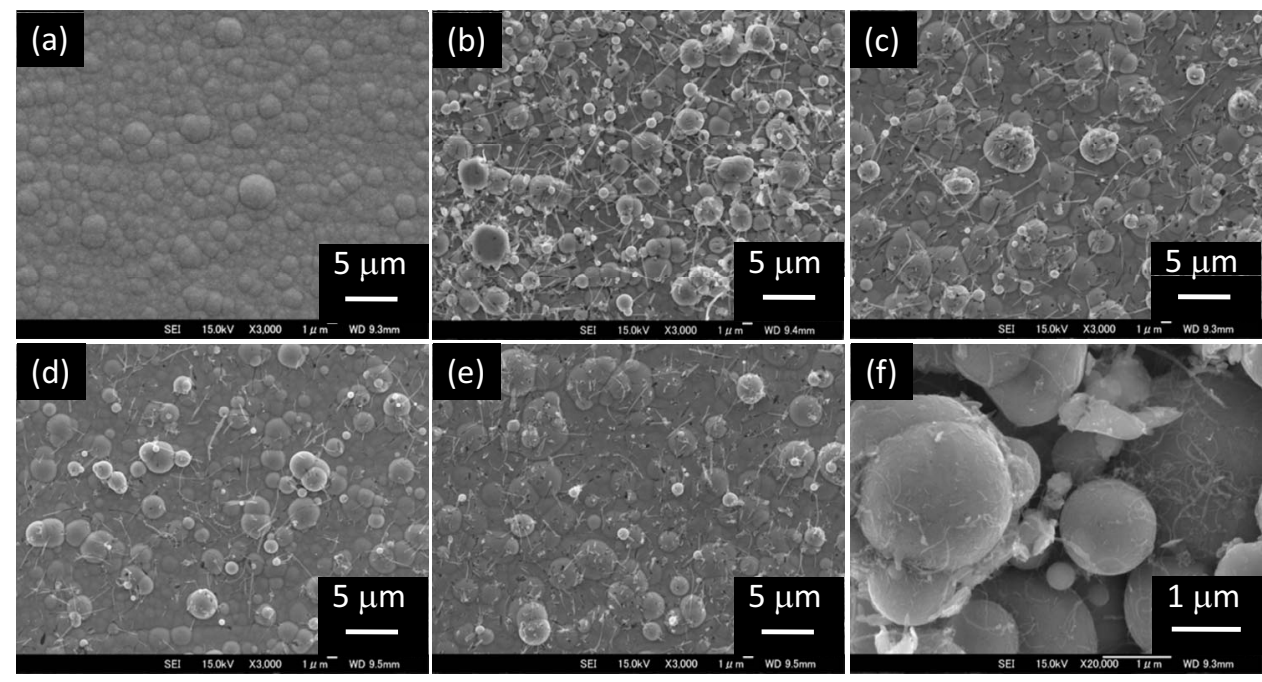

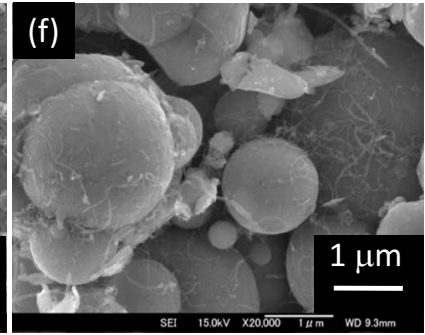

Figure 4. Surface SEM images of medium phosphorus-type Ni-P alloy/various MWCNT composite films: (a) Ni-P alloy, (b) Ni-P alloy/VGCF composite, (c) Ni-P alloy/cut-VGCF composite, (d) Ni-P alloy/VGNF composite, (e) Ni-P alloy/ cut-VGNF composite, and (f) Ni-P alloy/ Iljin composite film. Film thickness of all films is $\sim 4 \mu \mathrm{m}$. 

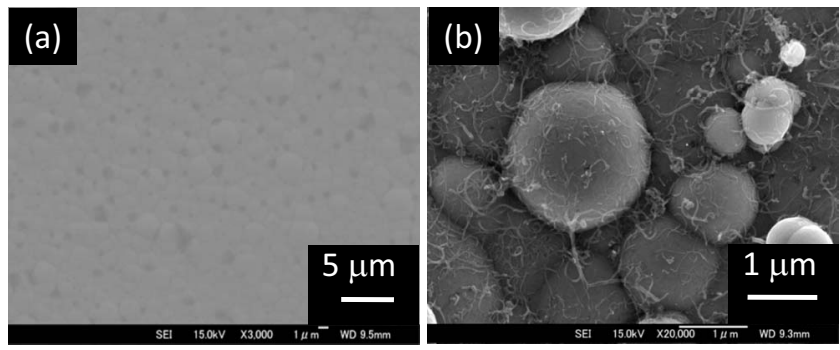

Figure 5. Surface SEM images of low phosphorus-type Ni-P alloy/lljin composite film. Film thickness is $\sim 4 \mu \mathrm{m}$.

diffraction patterns of electroless Ni-P alloy films after heattreatment for high, medium, and low phosphorus types, respectively. All the peaks, except for the copper substrate peaks, can be assigned to Ni-P alloy stable phases, which consist of the face-centered cubic
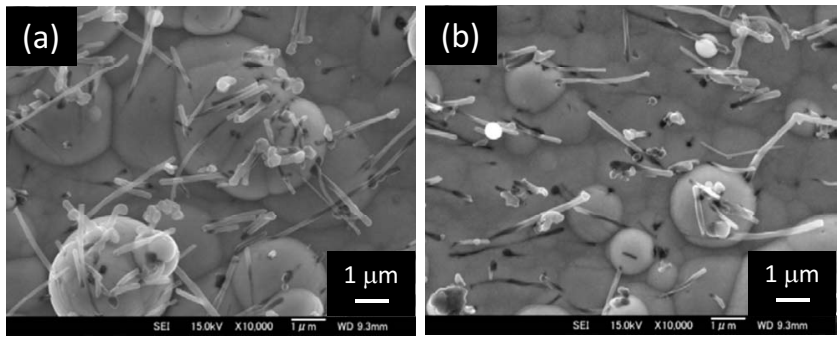

Figure 6. Surface SEM images of the medium phosphorus-type Ni-P alloy/ cut-VGCF composite films (a) before and (b) after heat-treatment. Film thickness is $\sim 4 \mu \mathrm{m}$. The heat-treatment condition was $400^{\circ} \mathrm{C}$ for $60 \mathrm{~min}$. nickel phase and the $\mathrm{Ni}_{3} \mathrm{P}$ compound phase. ${ }^{19}$ Also, the peak strength of the $\mathrm{Ni}_{3} \mathrm{P}$ compound phase increased with increasing phosphorus content in the alloy matrix. According to the $\mathrm{Ni}-\mathrm{C}$ binary alloy phase diagram, graphite does not form a stable compound with nickel below $500^{\circ} \mathrm{C} .{ }^{19}$ Therefore, the MWCNTs in the Ni-P alloy matrix did not form any compounds with the Ni-P alloy matrix during the heat-treatment. Figures 6 and 7 indicate that the heattreatment of the Ni-P alloy/MWCNT composite films only changed the phase structure of the Ni-P alloy matrix from a metastable amorphous or low crystallinity structure to a stable high crystallinity structure consisting of face-centered cubic nickel and a $\mathrm{Ni}_{3} \mathrm{P}$ compound phase.

Figure 8 shows the frictional behavior of the high phosphorustype Ni-P alloy/MWCNT composite films before and after heattreatment. For comparison, the frictional behavior of the high phosphorus-type Ni-P alloy film is also shown in the figure. Figures 9 and 10 show SEM images of the worn surfaces of the composite films (after 50 cycles) before and after the heat-treatment, respectively. Before the heat-treatment, the Ni-P alloy/MWCNT composite films show obviously lower friction coefficients compared to the $\mathrm{Ni}-\mathrm{P}$ alloy film (around 0.5 in the cycle number range of 10-50). The friction coefficients for $10-50$ cycles in ascending order is $\mathrm{Ni}-\mathrm{P}$ alloy/VGCF $\leq \mathrm{Ni}-\mathrm{P}$ alloy/VGNF $\leq \mathrm{Ni}-\mathrm{P}$ alloy/cut-VGCF $\leq \mathrm{Ni}-\mathrm{P}$ alloy/cut-VGNF $\leq \mathrm{Ni}-\mathrm{P}$ alloy/Iljin $« \mathrm{Ni}-\mathrm{P}$ alloy (Fig. 8a). In a previous study, Dickrell et al. measured the friction coefficients of vertically and transversely aligned MWCNTs to be 0.795 and 0.090, respectively, using a borosilicate glass pin as a counter surface under ambient conditions. ${ }^{20}$ Because the friction coefficients of the Ni-P alloy/MWCNT composite films ( $0.1-0.2$ for $10-50$ cycles) are comparable to that of the transversely aligned MWCNTs (0.090), the MWCNTs, which appear to lie in the plane of the composite films (Fig. 1-4), seem to affect their friction coefficients. The low friction coefficient of the transversely aligned MWCNTs is due to
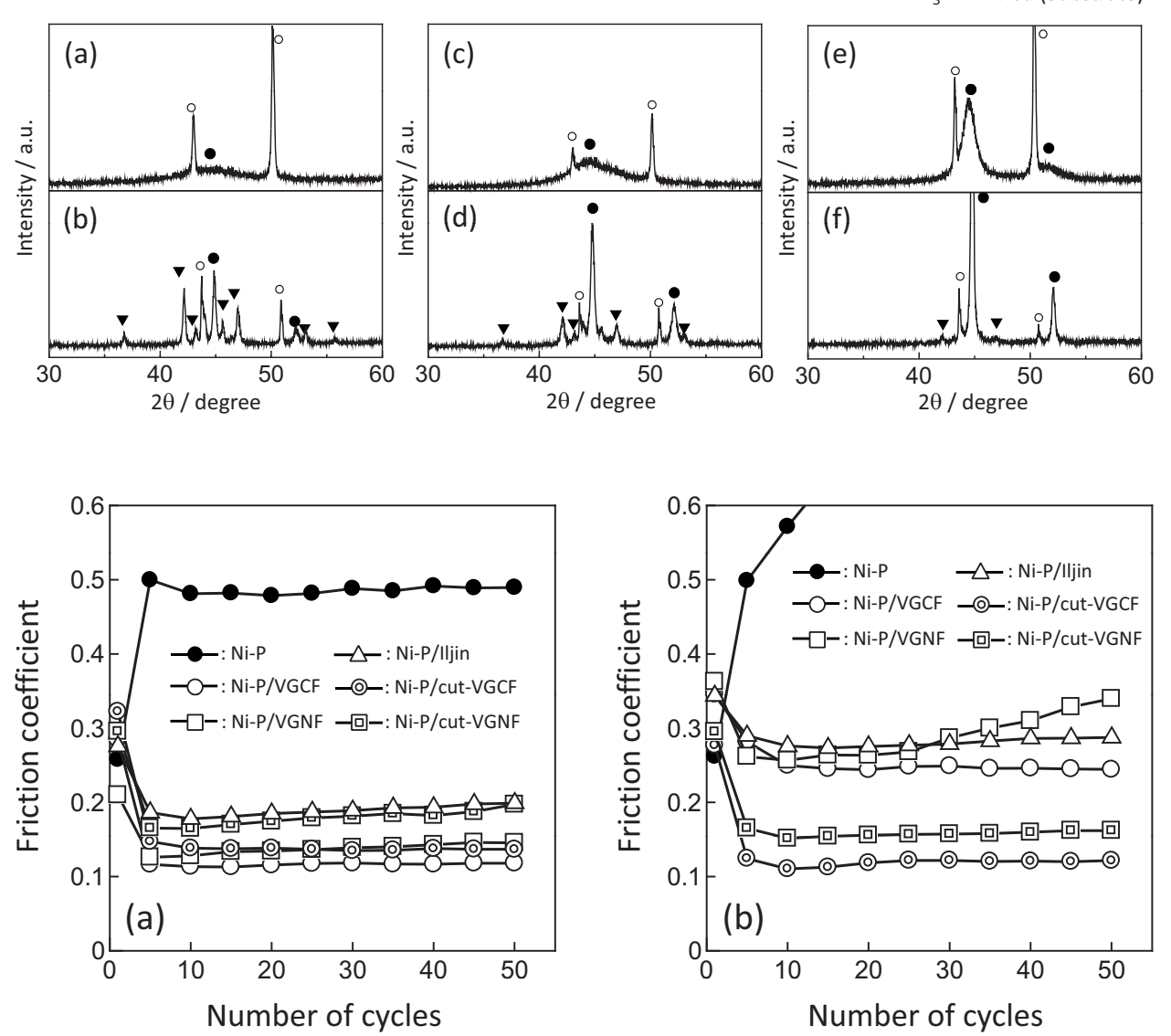

Figure 7. XRD patterns of various Ni-P alloy/MWCNT composite films: (a) High phosphorus-type Ni-P alloy/cut-VGCF composite film before heat-treatment, (b) high phosphorus-type Ni-P alloy/cutVGCF composite film after heattreatment, (c) medium phosphorus-type $\mathrm{Ni}-\mathrm{P}$ alloy/Iljin composite film before heat-treatment, (d) medium phosphorustype Ni-P alloy/lljin composite film after heat-treatment, (e) low phosphorus-type $\mathrm{Ni}-\mathrm{P}$ alloy/Iljin composite film before heat-treatment, and (f) low phosphorustype Ni-P alloy/Iljin composite film after heat-treatment. Film thickness of all films is $\sim 4 \mu \mathrm{m}$. The heat-treatment condition was $400^{\circ} \mathrm{C}, 60 \mathrm{~min}$.

Figure 8. Variation in friction coefficient as a function of number of cycles for the high phosphorus-type Ni-P alloy/various MWCNT composite films (a) before and (b) after heat-treatment. 

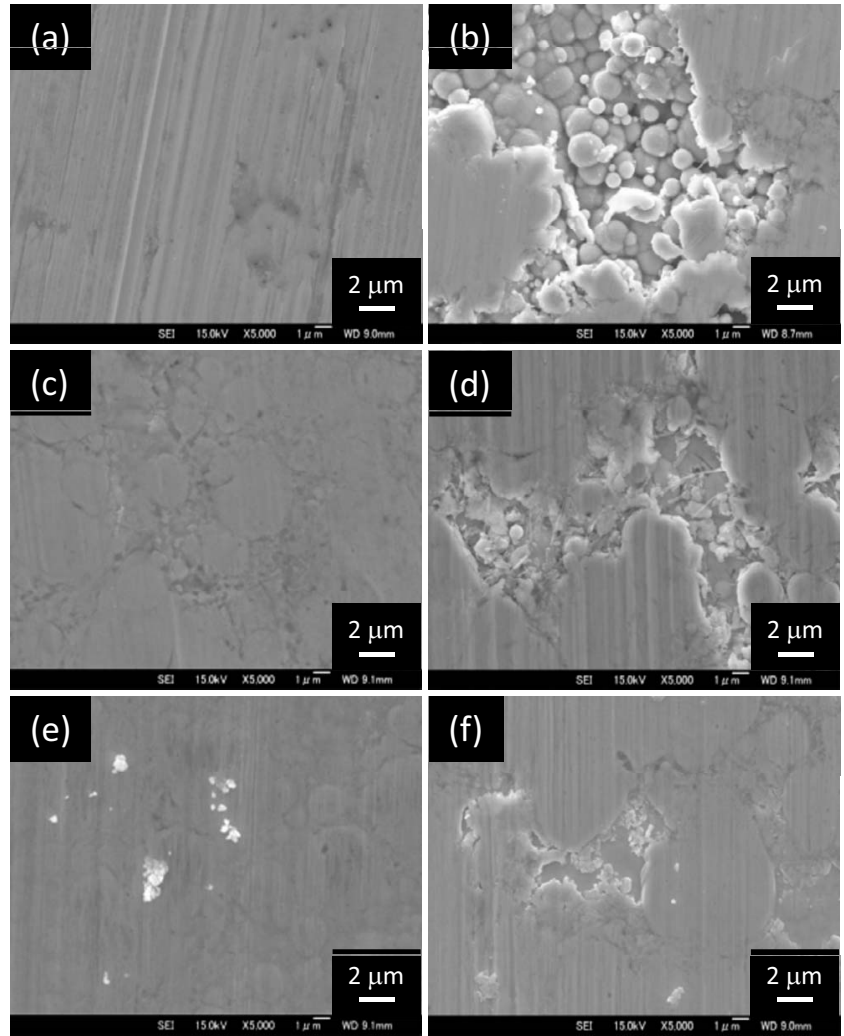

Figure 9. SEM images of worn surfaces of the high phosphorus-type films before heat-treatment: (a) Ni-P alloy, (b) Ni-P alloy/Iljin composite, (c) $\mathrm{Ni}-\mathrm{P}$ alloy/VGCF composite, (d) Ni-P alloy/cut-VGCF composite, (e) Ni-P alloy/VGNF composite, and (f) Ni-P alloy/cut-VGNF composite film.

their graphitic structure. As described above, the VGCFs and VGNFs are graphitized MWCNTs and might have graphitic structures with fewer defects than the Iljins. Thus, VGCFs and VGNFs, as well as cut-VGCFs and cut-VGNFs, have lower friction coefficients than the Iljins. This might be one of the reasons for the largest friction coefficient of the Ni-P alloy/lljin composite film. Comparing the cut-MWCNTs with the non-cut-MWCNTs, the former might have more defects on the side surfaces than the non-cut-MWCNTs owing to mechanical cutting. Furthermore, if the Ni-P alloy/ MWCNT composite films contain the same fraction of MWCNTs, the Ni-P alloy/cut-MWCNT composite films naturally include more tips of MWCNTs protruding on the surface, which should yield larger friction coefficients than the sides of the MWCNTs. These factors likely resulted in the ascending order of the friction coefficients observed.

After heat-treatment, the Ni-P alloy/MWCNT composite films also showed apparently lower friction coefficients compared to the $\mathrm{Ni}-\mathrm{P}$ alloy film (more than 0.6 after 15 cycles), and the order of ascending friction coefficient in the cycle number range of $10-50$ is $\mathrm{Ni}-\mathrm{P}$ alloy/cut-VGCF $\leq \mathrm{Ni}-\mathrm{P}$ alloy/cut-VGNF $\leq \mathrm{Ni}-\mathrm{P}$ alloy/VGCF $\leq \mathrm{Ni}-\mathrm{P}$ alloy/VGNF $\leq \mathrm{Ni}-\mathrm{P}$ alloy/Iljin $« \mathrm{Ni}-\mathrm{P}$ alloy (Fig. 8b). Compared to Fig. 8a, the order of the friction coefficients obviously changed. In particular, the friction coefficients of the Ni-P alloy/Iljin, Ni-P alloy/VGCF, and Ni-P alloy/VGNF composite films are higher than those before heat-treatment. Thus, the heattreatment clearly affected the friction coefficients of the composite films. Before heat-treatment, there are few abrasion particles from the composite films on the worn surfaces (Fig. 9). In contrast, after heat-treatment (Fig. 10b, c and e), abrasion particles can be seen on the worn surfaces of the Ni-P alloy/Iljin, Ni-P alloy/VGCF, and Ni-P alloy/VGNF composite films. The heat-treatment likely lowered the ductility of the composite films. The abrasion particles
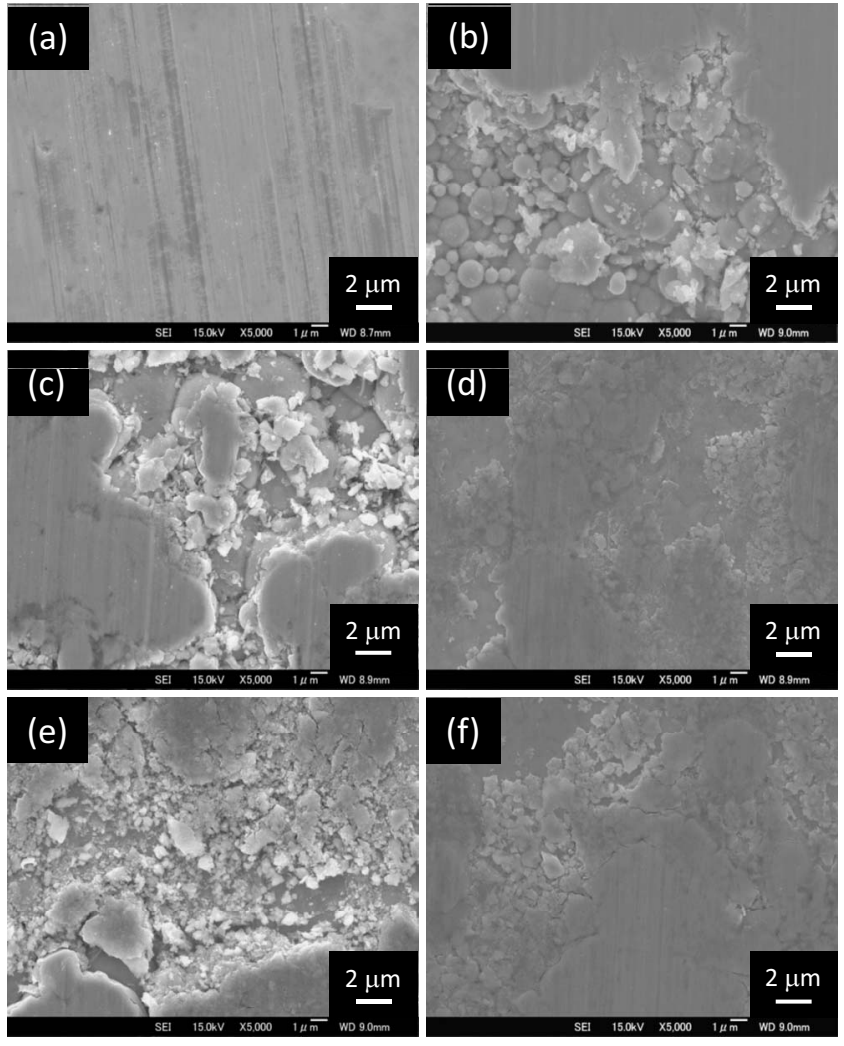

Figure 10. SEM images of worn surfaces of the high phosphorus-type films after the heat-treatment: (a) Ni-P alloy, (b) Ni-P alloy/Iljin composite, (c) $\mathrm{Ni}-\mathrm{P}$ alloy/VGCF composite, (d) Ni-P alloy/cut-VGCF composite, (e) Ni-P alloy/VGNF composite, and (f) Ni-P alloy/cut-VGNF composite film.

themselves and the metal oxide powders originating from them can affect the friction coefficients of the composite films. Therefore, the increase in the friction coefficients of the Ni-P alloy/Iljin, Ni-P alloy/VGCF, and Ni-P alloy/VGNF composite films might be related to the formation of the abrasion particles. In contrast, abrasion particles were not observed on the worn surfaces of the Ni-P alloy/ cut-VGCF and Ni-P alloy/cut-VGNF composite films (Fig. 10d and f). Therefore, when abrasion particles are not formed, the friction coefficients of the composite films containing cut-MWCNTs would be lower. Because the cut-VGCFs and cut-VGNFs are smaller or shorter than the VGCFs and VGNFs, if the same fraction of MWCNTs is incorporated in the composite films, larger numbers of cut-MWCNTs are naturally present in the composite films, resulting in more homogeneous microstructures (a typical microstructure is shown in Fig. 3e). Such a homogeneous microstructure, wherein MWCNTs act as reinforcement fibers, might suppress the generation of abrasion powders, resulting in lower friction coefficients of the Ni-P alloy/cut-MWCNT composite films.

Figure 11 shows the frictional behavior of the medium phosphorus-type Ni-P alloy/MWCNT composite films before and after heat-treatment. Before heat-treatment, the friction coefficients of the composite films are lower than those of the Ni-P alloy film in the cycle number range of 10-50. The friction coefficients of the $\mathrm{Ni}-\mathrm{P}$ alloy/MWCNT composite films, except for the Ni-P alloy/lljin composite film, were almost the same (around $0.11-0.13$ in the cycle number range of 10-50). In contrast, the friction coefficient of the $\mathrm{Ni}-\mathrm{P}$ alloy/Iljin composite film was especially high (around 0.310.33 in the cycle number range of 10-50). In addition to graphitization of the MWCNTs, other factors such as the number of Iljins on the film surface are related to the high friction coefficient. Undoubtedly, the number of Iljins on the surface of the medium phosphorustype Ni-P alloy/Iljin composite film is smaller than that of the Iljins 


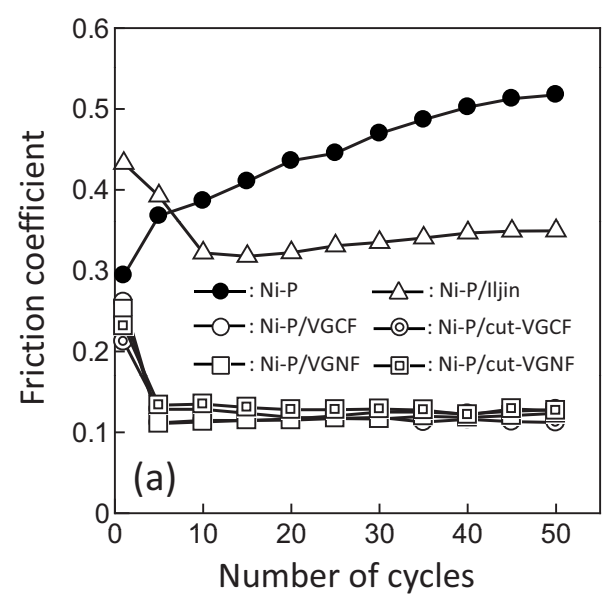

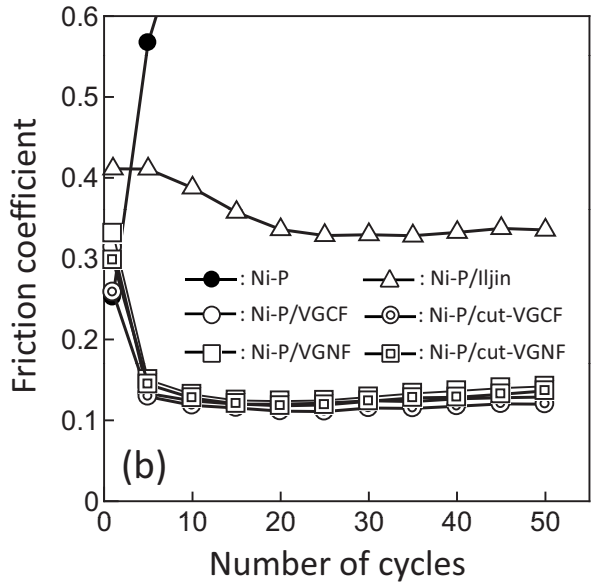

Figure 11. Variation in friction coefficient as a function of number of cycles for the medium phosphorus-type Ni-P alloy/ various MWCNT composite films (a) before and (b) after heat-treatment. on the surface of the high phosphorus-type Ni-P alloy/Iljin composite film (Fig. 4f and 5f), and the friction coefficient of the medium phosphorus-type Ni-P alloy/Iljin composite film is higher than that of the high phosphorus-type Ni-P alloy/Iljin composite film before heat-treatment $(0.18-2.0$ for $10-50$ cycles $)$. After heat-treatment, the friction coefficient of the medium phosphorus-type Ni-P alloy film increased (to more than 0.6 after 10 cycles) compared to that before heat-treatment $(0.38-0.52$ for $10-50$ cycles). In contrast, the friction coefficients of the composite films hardly changed before and after heat-treatment. From SEM observations of the worn surfaces of the medium phosphorus-type Ni-P alloy/MWCNT composite films (50 cycles) before and after heat-treatment, no abrasion particles were present in either case. This might indicate that the medium phosphorus-type Ni-P alloy/MWCNT composite films possess higher ductility than the corresponding high phosphorus-type composite films. The friction coefficients of the medium phosphorustype Ni-P alloy/MWCNT composite films might be determined mainly by the intrinsic lubricity of the MWCNTs on the film surfaces both before and after heat-treatment.

Figure 12 shows the frictional behavior of low phosphorus-type $\mathrm{Ni}-\mathrm{P}$ alloy/Iljin composite films before and after heat-treatment. For comparison, the frictional behavior of a low phosphorus-type Ni-P alloy film is also shown. Before heat-treatment, the Ni-P alloy/Iljin composite films show obviously lower friction coefficients $(0.17-$ 0.39 for $10-50$ cycles) compared to the Ni-P alloy film (more than 0.6 after 15 cycles) (Fig. 12a). After heat-treatment, the low phosphorus-type Ni-P alloy/Iljin composite film also showed a lower friction coefficient $(0.18-0.42$ for $10-50$ cycles $)$ compared to the low phosphorus-type Ni-P alloy film (more than 0.6 after 25 cycles). No significant amount of abrasion powder was observed on the worn surfaces of the composite films before or after heattreatment.

From Fig. 8, 11, and 12, the Ni-P alloy/MWCNT composite films obviously show lower friction coefficients compared to the $\mathrm{Ni}-\mathrm{P}$ alloy films regardless of the phosphorus content or the type or size of the MWCNTs both before and after heat-treatment. Strictly speaking, the precise amount of MWCNTs in the composite films and the exact number or coverage of MWCNTs on the film surfaces must be taken into account. Furthermore, the surface roughness of the composite films should also be considered. This will be carried out in a future work.

\section{Conclusions}

Various electroless Ni-P alloy/MWCNT composite films with different phosphorus contents and amounts of MWCNTs were fabricated and their frictional properties were investigated. High phosphorus-type Ni-P alloy/MWCNT composite films were successfully fabricated using various sizes of MWCNTs and they yielded lower friction coefficients compared to the high phosphorustype Ni-P alloy film both before and after heat-treatment. The friction coefficients were affected by heat-treatment. Medium phosphorus-type Ni-P alloy/MWCNT composite films were also successfully fabricated using various sizes of MWCNTs and these yielded lower friction coefficients than the medium phosphorus-type $\mathrm{Ni}-\mathrm{P}$ alloy film. The friction coefficients for these were not affected significantly by heat-treatment. Low phosphorus-type Ni-P alloy/ MWCNT composite films were fabricated using only the thinnest

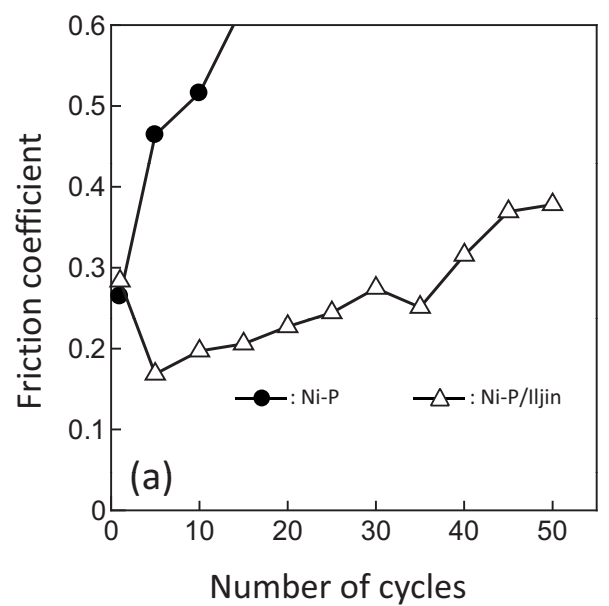

Number of cycles

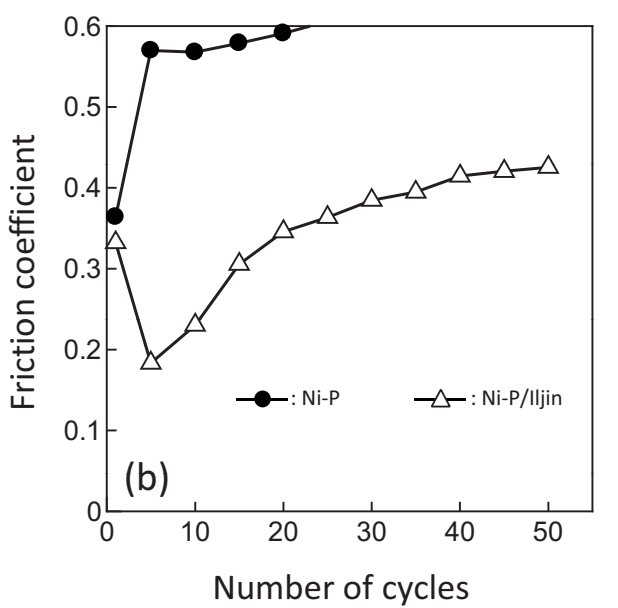

Figure 12. Friction coefficient as a function of number of cycles for the low phosphorus-type Ni-P alloy/lljin composite film (a) before and (b) after heattreatment. 
MWCNTs. These composite films showed lower friction coefficients than the low phosphorus-type Ni-P alloy films, and the friction coefficients were not affected by heat-treatment.

\section{Acknowledgments}

This research was supported by the Regional Innovation Cluster Program of Nagano, granted by MEXT, Japan.

Shinshu University assisted in meeting the publication costs of this article.

\section{References}

1. A. Brenner and G. Riddell, J. Res. Natl. Bur. Stand., 37, 31 (1946).

2. A. Oberlin, M. Endo, and T. Koyama, J. Cryst. Growth, 32, 335 (1976).

3. S. Tijima, Nature (London), 354, 56 (1991).

4. J. Tan, T. Yu, B. Xu, and Q. Yao, Tribol. Lett., 21, 107 (2006).

5. B. M. Praveen, T. V. Venkatesha, Y. Arthoba Naik, and K. Prashantha, Surf. Coat. Technol., 201, 5836 (2007).

6. S. Arai and M. Endo, Electrochem. Commun., 5, 797 (2003).

7. S. Arai and M. Endo, Electrochem. Solid-State Lett., 7, C25 (2004).

8. S. Arai, T. Saito, and M. Endo, J. Electrochem. Soc., 154, D530 (2007).
9. S. Arai, T. Saito, and M. Endo, J. Electrochem. Soc., 157, D147 (2010).

10. W. X. Chen, J. P. Tu, H. Y Gan, Z. D. Xu, Q. G. Wang, J. Y. Lee, Z. L. Liu, and X. B. Zhang, Surf. Coat. Technol., 160, 68 (2002).

11. X. H. Chen, G. Zhang, C. S. Chen, L. P. Zhou, S. L. Li, and X. Q. Li, Adv. Eng. Mater, 5, 514 (2003).

12. W. X. Chen, J. P. Tu, Z. D. Xu, W. L. Chen, X. B. Zhang, and D. H. Cheng, Mater. Lett., 57, 1256 (2003).

13. W. X. Chen, J. P. Tu, L. Y. Wang, H. Y. Gan, Z. D. Xu, and X. B. Zhang, Carbon, 41, 215 (2003)

14. L. Y. Wang, J. P. Tu, X. W. Chen, Y. C. Wang, X. K. Liu, C. Olk, D. H. Cheng, and X. B. Zhang, Wear, 254, 1289 (2003).

15. Z. Yang, H. Xu, Y. L. Shi, M. K. Li, Y. Huang, and H. L. Li, Mater. Res. Bull., 40, $1001(2005)$.

16. X. H. Chen, C. S. Chen, H. N. Xiao, H. B. Liu, L. P. Zhou, S. L. Li, and G. Zhang, Tribol. Int., 39, 22 (2006).

17. K. C. Park, M. Fujishige, K. Takeuchi, S. Arai, S. Morimoto, and M. Endo, J. Phys Chem. Solids, 69, 2481 (2008).

18. M. Endo, CHEMTECH, 18, 568 (1988).

19. The Materials Information Society, Binary Alloy Phase Diagrams, 2nd ed., ASM International, Materials Park, OH (1996).

20. P. L. Dickrell, S. B. Sinnott, D. W. Hahn, N. R. Raravikar, L. S. Schadler, P. M. Ajayan, and W. G. Sawyer, Tribol. Lett., 18, 59 (2005). 